\title{
Biological processes affecting energy efficiency and energy saving in the technology of fermented milk products
}

\author{
Vera Ganina ${ }^{1 *}$, Irina Krasnova ${ }^{2}$ \\ ${ }^{1}$ K.G. Razumovsky Moscow State University of technologies and management \\ (the First Cossack University), Laboratory of Design and implementation of personalized \\ food products and diets, 109004Zemlyanoy Valstreet 73, Russia \\ ${ }^{2}$ Moscow State University of food production, Department of technology and biotechnology \\ of milk and dairy products, 109316Talalikhina street 33, Russia
}

\begin{abstract}
The production of dairy products is classified as an energyconsuming industry, which is due to the use of heat exchange processes involving steam as a heat carrier. Indicators of energy efficiency and energy conservation in the production of fermented milk products, including cottage cheese, may sharply decrease due to violations of the fermentation process of raw milk. The intervention of a biological factor the development of viruses that lyse the cells of lactic acid bacteria, leads to the inhibition or suspension of fermentation. This affects the quality and safety of resulting products and the need to re-implement technological processes that increase energy consumption. Researches on the detection of bacteriophages in the course of technological processes for the production of cottage cheese and yogurt showed the presence of phages at all stages of the technology of fermented milk products. Areas were identified where bacteriophages were detected in large numbers, which could negatively affect the fermentation process of raw milk. The data obtained allowed us to identify critical control points in the technology of cottage cheese and yogurt, where bacteriophages should be monitored to prevent a decrease in energy efficiency and occurrence of additional energy costs.
\end{abstract}

\section{Introduction}

The issues of improving energy efficiency at food enterprises are always in the spotlight, which is evidenced by the Energy Strategy of Russia for the Period up to 2030 approved by the Decree of the Government of the Russian Federation and the Law «On Energy Conservation and on Improving Energy Efficiency and Amendments to Certain Legislative Acts of the Russian Federation». The food industry, including the dairy industry, is one of the main components of the economic security of each country. Milk, fermented milk and other types of dairy products play an important role in the nutrition of the population. Constantly developing technologies are aimed at improving the quality and safety of

\footnotetext{
* Corresponding author: vigan5428@yandex.ru
} 
various types of dairy products, including those that have improved consumer, functional and special properties. Innovative technologies of dairy products will be competitive and in demand only if they are energy efficient [1]. When processing raw milk into products, heat exchange processes are used at different stages of the technological process, with the involvement of steam as a heat carrier, which causes high energy costs. Such stages in the production of fermented milk products, including cottage cheese, include: milk pasteurizing plants, production lines of drinking fermented milk products, cottage cheese, sour cream, as well as CIP stations for washing equipment. To ensure maximum energy efficiency of technological processes of dairy products, enterprises use a complex of various technical operations, which implementation leads to the reduction in energy consumption [2]. The most important tasks of the development of energy-saving technologies in the dairy industry include improving the quality and safety of products, deep and complete processing of raw milk, reducing losses, improving environmental friendliness of enterprises, etc. During the transition of enterprises to the best available technologies and preparation of the second edition of the information and technical reference book "Production of Beverages, Milk and Dairy Products", energy consumption of whole-milk products' technologies was researched. It was evaluated by the process parameters and technical characteristics of equipment used. The results of the obtained data indicated the highest energy consumption in the production of cottage cheese, which is higher by an order of magnitude if compared to the production of drinking milk and fermented dairy products. The specific costs of heat and refrigeration energy in the production of cottage cheese were higher than in the technology of other fermented dairy products $[3,4,5]$. Speaking about energy conservation and energy efficiency of technological processes of fermented milk products, they practically do not take into account the violation of the fermentation process of raw milk as a result of the effect of a biological factor - the development of bacteriophages. The violation of the fermentation process in the production of fermented dairy products can lead not only to the development of the final product that does not meet requirements of regulatory documentation, but also dangerous in microbiological terms. Information about the situations associated with dairy poisoning is reflected in the publications of scientists from different countries [6, 7]. The phenomenon of bacteriophagy occurs in almost every dairy enterprise, which often leads to the need to re-process the resulting non-standard fermented milk product and, as a result, to increased costs and reduced energy efficiency [8,9]. Despite the fact that the phenomenon of bacteriophagy has been known and researched for a long time, the problem continues to arise in dairy enterprises, leads to negative results and stimulates further research $[10,11,12,13]$.

The aim of the research was to study the sources of bacteriophages that inactivate lactic acid bacteria of starter cultures during the production of cottage cheese and yogurt, as well as to determine critical control points during the monitoring of phages.

\section{Materials and methods}

The objects of researches were raw milk and cream, pasteurized normalized milk, starter cultures, equipment blanks, cottage cheese, whey, yogurt, and bacteriophages.

Quality and safety indicators in raw milk and cream, ready-made cottage cheese and yogurt were determined by standard methods. Sampling and their preparation for microbiological researches were carried out according to GOST 26809.1. - 2014. The following physical and chemical parameters were controlled: density in raw milk according to GOST 54758-2011, the content of protein was determined by the Kjeldahl method, the content of nonfat milk solids in raw milk - according to GOST R 54761-2011, the content of fat - by the acid method according to GOST 5867, the content of moisture - 
according to GOST 3626, titrated acidity - according to GOST R 54669-2011. Some safety indicators, including microbiological ones, were evaluated in accordance with TR CU 033/2013, namely, in raw milk: the number of somatic cells - according to GOST 234532014, the content of antibiotics - according to GOST 32219-2013, the number of mesophilic aerobic and facultative anaerobic microorganisms in raw milk - according to GOST 32901-2014; in cottage cheese and yogurt: the number of coliform bacteria according to GOST 32901-2014, the number of yeast and mold - according to GOST 33566-2015, the number of lactic acid microorganisms - according to GOST 33951-2016. Sensorial evaluation (taste, colour, smell, consistency) were determined according to GOST R ISO 22935-2-2011. The detection of bacteriophages was carried out using a previously developed method [14].

Since the parameters of energy conservation and energy efficiency depend on the technological modes of the processes and equipment included in the production lines of fermented dairy products, the researches were carried out for periodic and line methods for the production of cottage cheese, and the tank method for the production of yogurt. All samples were provided by enterprises that had problems with the violation of fermentation processes in the production of cottage cheese and yogurt. There were researched: 34/32 samples of raw milk, 27/23 - raw cream, 9/8 - bulk starters, 22/23 - pasteurized normalized milk, 22/23 - equipment blanks, 22/23 - cottage cheese and 22/23 - whey in the course of the technology of cottage cheese, which was produced by periodic and line methods. There were researched 29 samples of raw milk, 21 - raw cream, 7 - starter cultures, 19 pasteurized normalized milk, 19 - equipment blanks and 19 - yogurt in the course of the technology of yogurt obtained by the tank method.

The results are presented as the values \pm Standard Deviation (SD). Tukey's test $(p<0.05)$ was used to detect significant differences between treatments. P-values below 0.05 were considered significant.

\section{Results and discussion}

The Hazard Analysis and Critical Control Points safety management system, implemented in the dairy industry, provides for the establishment and monitoring of critical control points of biological hazards [15]. Bacteriophages that inactivate lactic acid bacteria of starter cultures should be classified as biological hazards. Conducting researches to establish critical control points when monitoring bacteriophages in the technology of cottage cheese and yogurt is due to the following reasons. First of all, technological processes of these products differ in energy consumption, and secondary, the biological factor - inhibition or stopping of the fermentation process as a result of the development of bacteriophages is not taken into account when evaluating energy efficiency. The frequency of detection of phage particles in the researched samples during the production of cottage cheese by different methods and yogurt is shown in Figure 1. 


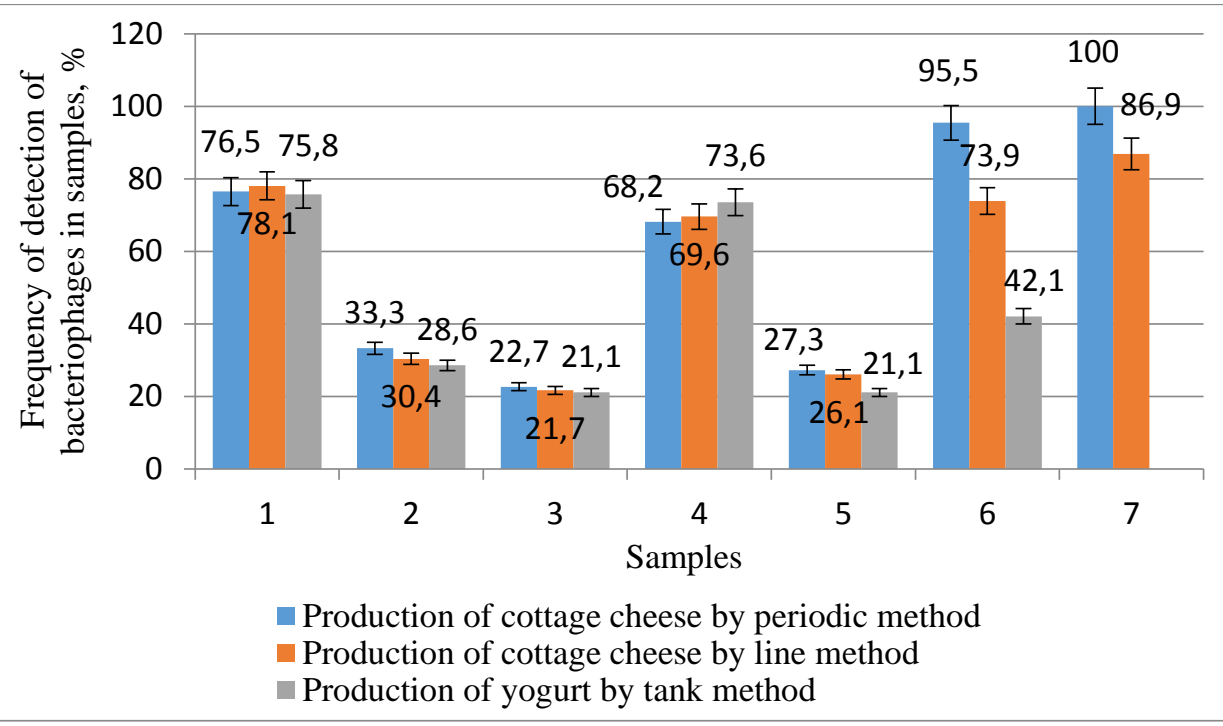

Fig. 1. Frequency of detection of bacteriophages in the course of cottage cheese and yogurt technology ( 1 - raw milk, 2 - raw cream, 3 - bulk starters, 4 - pasteurized milk, 5 - equipment blanks, 6 - ready-made cottage cheese/yogurt, 7 - whey).

Bacteriophages were found throughout the entire course of the researched technological processes for the production of cottage cheese and yogurt. Phages were most often detected in samples of raw milk $75.8 \%-78.1 \%$; pasteurized milk - 68.2\%-73.6\%; in finished products - 42.1\% - 95.5\%; curd whey - 86.9\%-100.0\%. It should be noted that bacteriophages were less frequently detected in raw cream, bulk starters, and equipment blanks. The analysis of the data obtained shows that the process of fermentation in the production of fermented dairy products almost always takes place in conditions of phage infection. When a critical amount of phage particles is reached in a container, where the fermentation process of dairy raw materials takes place, the process may not only slow down, but also stop, which will lead to the need for the re-processing of raw materials. To reduce the spread of bacteriophages in production and prevent emerging risks, phages were isolated from the researched objects and their spectrum of lytic action was determined. In the technology of cottage cheese, the enterprises used starter cultures, which included mesophilic lactococci (Lactococcuslactis subsp. lactis, Lactococcuslactis subsp. cremoris, Lactococcuslactis subsp. lactisbiovar. diacetilactis) or mesophilic lactococci and thermophilic lactic streptococci (Streptococcus salivarius subsp. thermophilus). The starter cultures used in the yogurt technology consisted of lactobacilli (Lactobacillus delbrueckii subsp. bulgaricus) and thermophilic lactic streptococci. That is why we researched the effect of isolated bacteriophages on lactic acid bacteria of the above-listed species. It was revealed that some isolated bacteriophages inactivated the bacteria of the Lactococcus genus, the seconds - Streptococcus salivarius subsp. thermophilus, and the thirds Lactobacillus delbrueckii subsp. bulgaricus), including those that are a part of starter cultures used in the surveyed enterprises. (Figure $2 \mathrm{a}, \mathrm{b}, \mathrm{c}$ ). 


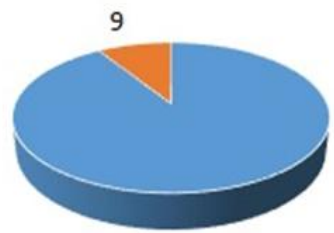

91

a

" The number of resistant cultures

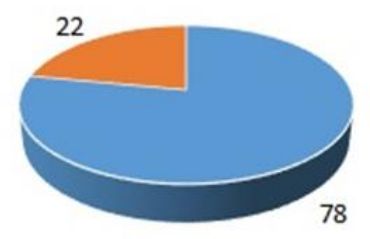

b

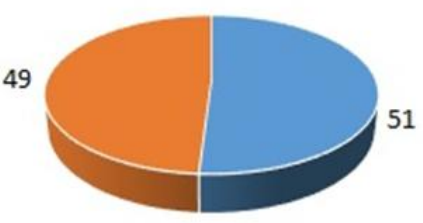

$c$

- The number of sensitive cultures

Fig. 2. The number of resistant and sensitive cultures: a - lactobacilli, b - thermophilic lactic streptococcus, $\mathrm{c}-$ lactococci.

The results obtained are consistent with the data of other authors and indicate that cultures of mesophilic lactococci are most affected by phages, thermophilic lactic streptococci are somewhat less affected, while lactobacilli are the least affected. However, all sensitive cultures can be inactivated by bacteriophages and contribute to the production of non-standard fermented dairy products.

\section{Conclusion}

Based on the conducted researches, critical control points were identified in the technology of cottage cheese and yogurt produced at the surveyed dairy enterprises. The established critical control points should be monitored to prevent a decrease in the activity of the lactic acid process and the occurrence of situations for additional processing of raw milk and energy costs associated with this process. The results of the research formed the basis for the developed recommendations for the implementation of corrective measures in the production of cottage cheese produced by periodic and line methods, as well as yogurt produced by the tank method.

\section{References}

1. V.D. Kharitonov, Dairy ind.5, 28-9 (2020)

2. V.N. Brovtsin, A.F. Erk, O.V. Kovaleva, Collection of scientific papers GNU SZNIIMESH Russian Agricultural Academy 85, 95-100 (2014)

3. A.A. Kuzin, V.A. Grunskaya, N.G. Ostretsova, L.A. Builova, V.A. Shokhalov, Dairy in.10, 29-31 (2017)

4. Best Available Techniques (BAT) Reference Document for the Food, Drink and Milk Industries. Industrial Emissions Directive 2010/75 / EU (Integrated Pollution Prevention and Control).

5. A.A. Kuzin, V.A. Shokhalov, V.A. Grunskaya, V.B. Shevchuk, I.A. Evdokimov, A.D. Lodygin, Dairy ind.2, 30-31 (2021)

6. S. Lin, L. Yang, G. Chen, B. Li, Z. Xu, Microb. Pathog. 111, 285-291 (2017)

7. N.R. Efimochkina, Dairy ind.2, 36-40 (2019)

8. V.I. Ganina, Dairy ind.2, 41-43 (2016)

9. S. A. Pujato, A.D. Pujato, J. Quiberoni, S.A. Mercanti, J. Appl. Microb. 126 (1), 14-30(2019) 
10. N.P. Sorokina, I.V. Kucherenko, E.V. Kuraeva, L.V. Kushnarenko, Dairy ind.2, 32-34 (2019)

11. V.I. Ganina, Dairy ind.3, 31-32 (2020)

12. M.C. García-Anaya, D. R. Sepulveda, A.I. Sáenz-Mendoza, C. H. Acosta-Muñiz, Trends in Food Sci. and Technol. 95, 10-20 (2019)

13. E. K. Tayyarcan, E. AcarSoykut, I. H. Boyaci, Folia Microb, 63(5), 627-636 (2018)

14. J. E. Garneau, S. Moineau, Microb. Cell Factories. 10, 20 (2011)

15. V.I. Ganina, I.R. Volkova, L.V. Kalinina, Dairy ind.12, 39-40 (2006)

16. E.L. Bortsova, L.Yu. Lavrova, Dairy ind.10, 27-30 (2020) 